\title{
The Burden of COVID-19 in Canada
}

\section{Simona Bignami ${ }^{1}$}

Received: 30 August 2021 / Accepted: 31 August 2021 / Published online: 4 October 2021 (c) The Author(s), under exclusive licence to Springer Nature Switzerland AG 2021

Two years ago, when I became editor of Canadian Studies in Population, no one would have imagined that, only a year later, the world would be in the midst of the most devastating pandemic of modern times.

Canada has so far experienced three waves (Fig. 1) and many provincial epidemics of the new coronavirus disease (COVID-19). At the end of its third wave (July 21, 2021), Canada ranked 7th in cases per capita, and 6th in COVID-19-related deaths per capita among high-income, medium-large peer countries (Australia, France, Germany, Italy, Japan, South Korea, Spain, Taiwan, the UK, the USA). These statistics, however, fail to demonstrate the heterogeneity in the provincial experiences of COVID-19. For example, the province of Québec had a per-capita COVID-19 mortality rate (130.9 per 100,000) close to France (165.5 per 100,000) (Little, 2021; Roser et al., 2021), while the provinces in the Atlantic "bubble" (Nova Scotia, New Brunswick, Prince Edward Island and Newfoundland and Labrador) and the Northern Territories have recorded fewer than 10,000 cases and 500 deaths (Little, 2021), thanks to the COVID elimination strategy they adopted since the beginning of the pandemic.

These statistics reflect not only specific pandemic dynamics, but also different public health measures adopted at the provincial level. Although several improvements were made to improve federal provincial collaboration following the 2003 SARS outbreak (Webster, 2020), Canadian provinces have used their administrative authority over health care to forge individual responses to COVID-19. Despite early lockdowns in March 2020, the first wave of the pandemic hit Québec and Ontario particularly hard, where COVID-19 spread almost unchecked in long-term care facilities (Bignami, 2021; Canadian Institute for Health Information, 2020; Decarie \& Michaud, 2021; Detsky \& Bogoch, 2020; Fisman et al., 2020). After a quiet summer at the end of the first pandemic wave, in Fall 2020 across most provinces, school openings have been the catalyst for the second wave (Bignami et al., 2021a), similar to the experiences of other countries (Bignami et al., 2021b; Gurdasani et al., 2021). On the contrary, the third pandemic wave has been more unevenly distributed, owing

Simona Bignami

simona.bignami@umontreal.ca

1 Département de Démographie, Université de Montréal, Montréal, Canada 


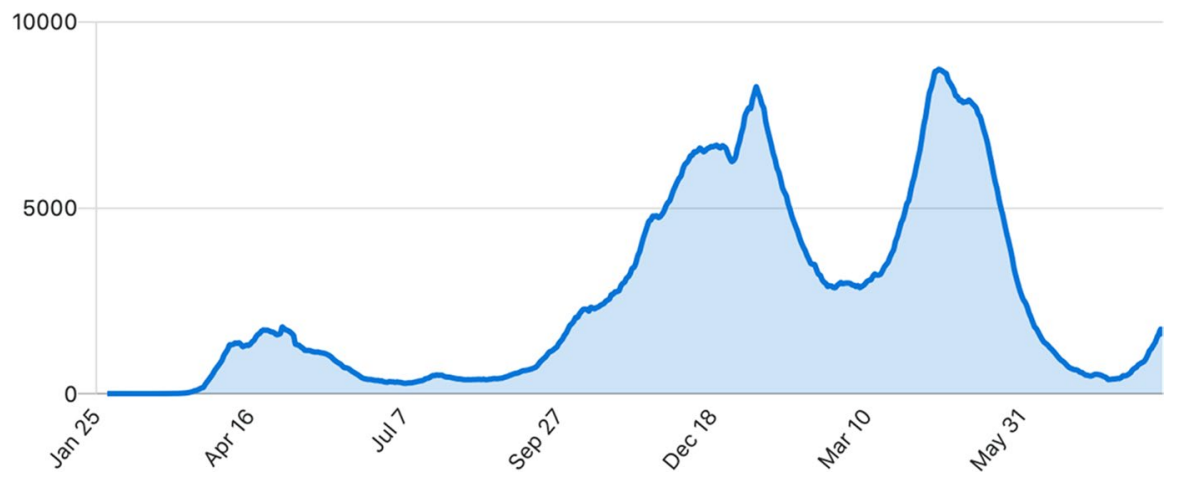

Fig. 1 Seven-day rolling average of new confirmed cases of COVID-19 in Canada, January 25, 2020July 27,2021

to the different pace of COVID-19 vaccinations and the spread of COVID-19 variants across Canada's provinces.

Quantifying the sociodemographic dimensions and impact of COVID-19 in Canada at the provincial level has been, and still is, made difficult by the limited amount of comparable data, which Canadian scholars have highlighted since the early days of the pandemic (Berry et al., 2020; Peloquin, 2020). Data gaps persist for population subgroups that have been disproportionately affected by the pandemic, such as immigrants and visible minorities (Choi et al., 2021; Subedi et al., 2020). Etowa et al., (2021), Ilene Heyman presents a framework to strengthen the collection and use of disaggregated data to understand and monitor the risk and burden of COVID19 among racialized populations, and includes recommendations to policymakers and community stakeholders to fill these gaps.

The main available data source containing basic demographic information about individuals who have tested positive for SARS-CoV-2, the virus that causes COVID-19, has been available at the provincial level through the concerted efforts of the Public Health Agency of Canada and Statistics Canada since May 2020 (Statistics Canada, 2021a). ${ }^{1}$ By exploiting these data, Fig. 2 allows visualising geographic differentials in the burden of COVID-19 in Canada according to age and sex, which are well established as two key risk factors for infection and severe outcomes related to the disease (Karmakar et al., 2021; Pijls et al., 2021). This figure shows that the age and gender distribution of confirmed positive cases is similar across provinces. The highest cumulative prevalence of infection is found among 20-29 years old and decreases with age thereafter, only to increase steeply among 80+years old. The main exception is Québec, where infection

\footnotetext{
${ }^{1}$ As of July 9, 2021, the dataset includes information on 90-100\% of COVID-19 cases and related fatalities recorded at the provincial level. Coverage of hospitalisation status is also $90-100 \%$ complete in all provinces except for Ontario, where information on hospital status is missing for almost $80 \%$ of confirmed cases. Information on the age and gender characteristics of confirmed positive cases is $99 \%$ complete in all provinces.
} 


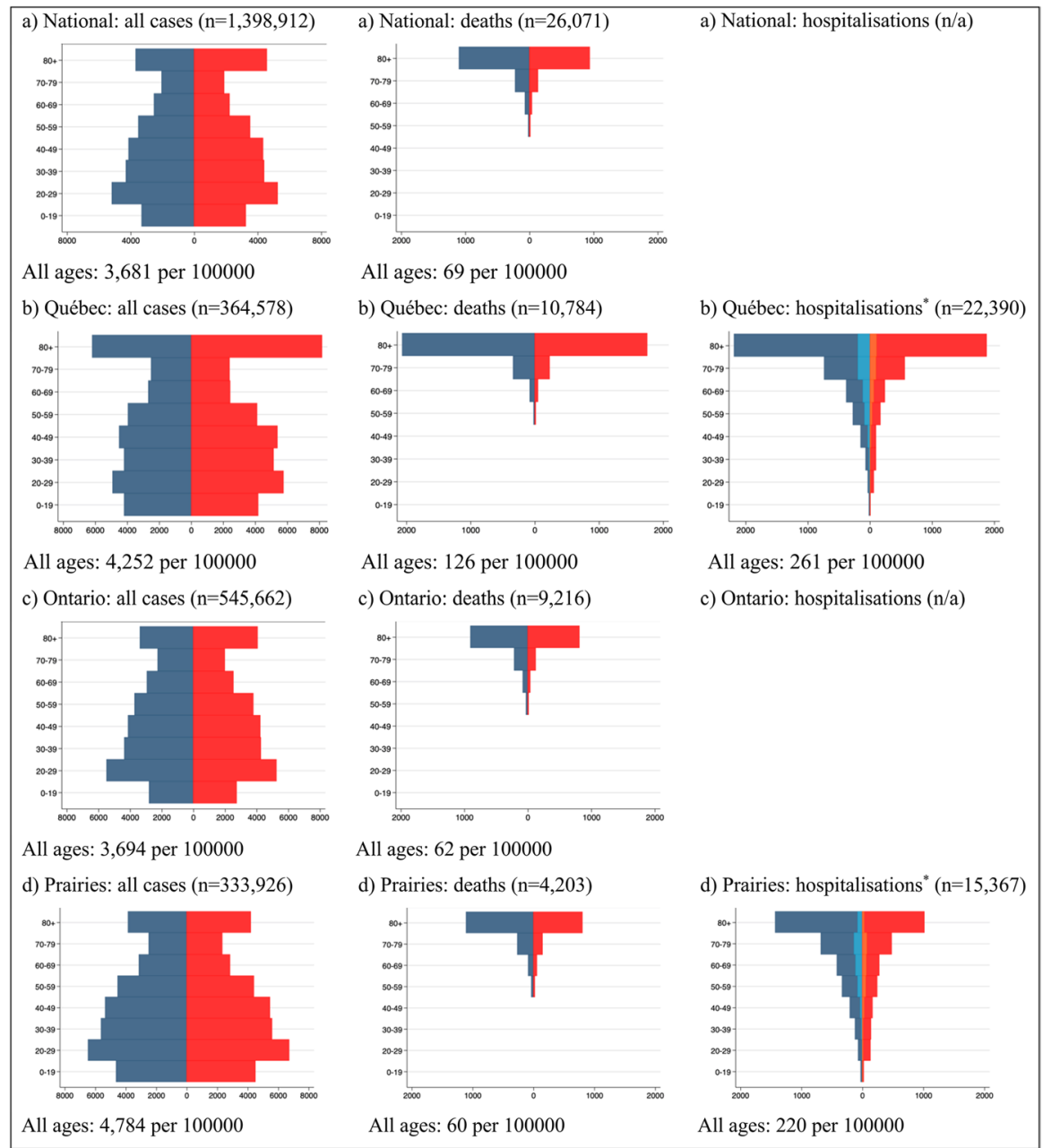

Fig. 2 Age-sex pyramids of COVID-19 cases, deaths and hospitalisations (with and without ICU admission*) per 100,000 population, by region, January 25, 2020-July 9, 2021

rates among the latter group are the second highest after 20-29 years old, and where infection rates among 0-19 years are the highest in Canada and close to those for 20-29 years old. In addition, in Québec and British Columbia, infection rates among 30-39, 40-49 and 50-59 years old are similar, rather than decreasing with age. The burden of mortality for COVID-19 has been carried by the elderly. Consistent with the high rates of COVID-19 mortality among long-term care residents (see Decarie \& Michaud, 2021), fatalities are concentrated above age 70 for both men and women. Furthermore, the largest number of COVID-19-confirmed positive cases who died is among those age $80+$ years in all provinces, especially in Québec. Even though COVID-19-related fatalities are concentrated among the elderly, hospitalisation needs have been felt in all age groups. In addition, the 


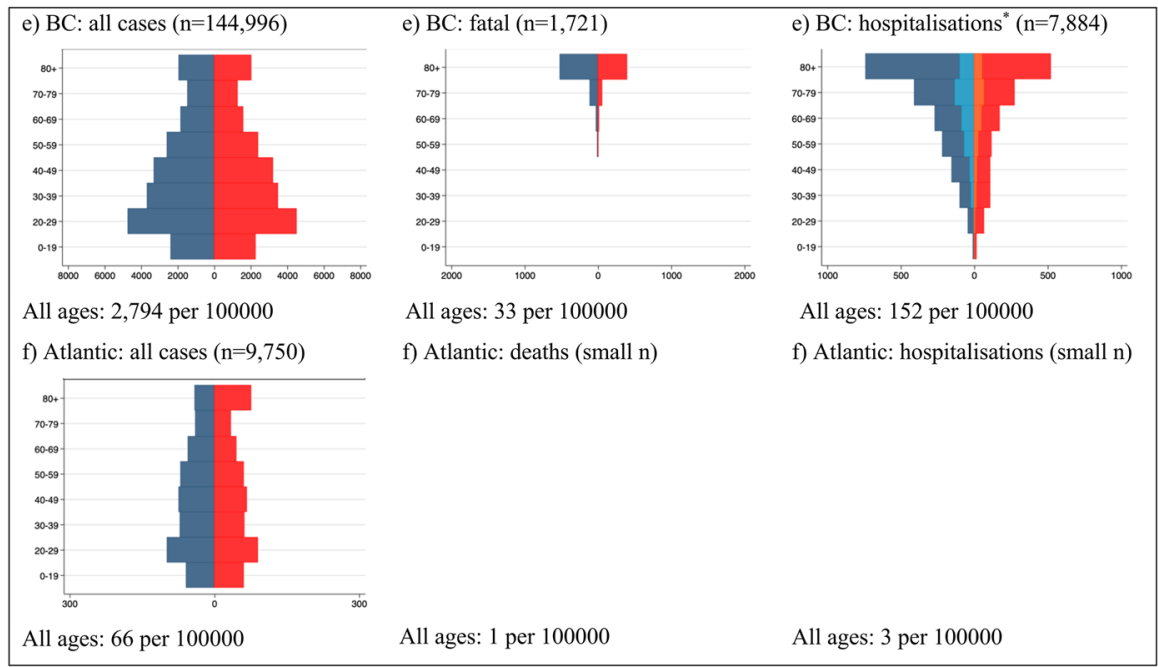

\footnotetext{
* In the age-sex pyramids for hospitalisations, individuals who were hospitalised and required intensive care (ICU) are represented in paler colour.

Legend: Blue: Male; Red: Female.

Notes: To ensure confidentiality, some provinces/territories have been grouped together (see Statistics Canada 2021a). Ontario refers to Ontario and Nunavut. Prairies include Alberta, Manitoba and Saskatchewan as well as the Northwest Territories. British Columbia (BC) refers to British Columbia and Yukon. Atlantic provinces include New Brunswick, Nova Scotia, Prince Edward Island and Newfoundland and Labrador. Hospitalisations are not presented for Ontario or the national level due to the large proportion of missing values in the former case (close to $80 \%$; see footnote 1 ).

Sources: Number of COVID-19 cases, deaths and hospitalisations are from Statistics Canada (2021a). Population denominators are from Statistics Canada (2021b).
}

Fig. 2 (continued)

number of men who are hospitalised and, especially, admitted to intensive care has been higher for men than for women.

The papers included in this double issue's special section on population health and COVID-19 focus on one of the main consequences of the COVID-19 pandemic, that is, excess mortality, in Canada and abroad. These papers were solicited through a special call for papers in late 2020, under the auspices of five scholars that have been heavily involved in research and public advocacy during the pandemic. Daniela Ghio, a scientific expert at the Joint Research Centre of the European Commission, is responsible for appraising demographic approaches to measuring mortality, morbidity and health, stressing the impacts of the COVID-19 pandemic on the demographic regime and studying the implications for health care demand and utilisation heterogeneities across countries. Enrique Acosta, a research scientist in the Laboratory of Population Health at the Max Plank Institute for Demographic Research, has been leading the creation of COVerAGE-DB, a unique database that aims to provide global coverage of key demographic aspects of COVID-19 cases, deaths and tests in an open-access format (Riffe et al., 2021). David Fisman is an infectious disease physician and epidemiologist at the University of Toronto's Dalla Lana School of 
Public Health, who has been a member of the Ontario's COVID-19 Science Table between January and August 2021. Andrew Noymer is a medical demographer and epidemiologist at the University of California, Irvine, whose research focuses on pandemic mortality. During the COVID-19 pandemic, he has worked to help the public understand ongoing events, being quoted in the press hundreds of times (including the New York Times, Washington Post and The Atlantic) and receiving the prestigious UC Irvine's campus-wide faculty senate service award for 2020-21 for his work on public engagement. Nikolaos Stilianakis is a senior scientist at the Joint Research Centre of the European Commission and associate professor of epidemiology and biomathematics at the University of Erlangen-Nuremberg/Germany, whose research focuses on infectious disease epidemiology with an emphasis in mathematical modelling, theoretical immunology/viral dynamics and environmental health.

In their guest editorial, Ghio et al., (2021) give important insights about how the impact of COVID-19 in Canada compares with a selected number of Western countries. Beyond mortality, however, Ana Fostik's (2021) commentary is an important reminder that the COVID-19 pandemic has far-reaching consequences for fertility and family formation as well. This, in turn, will foster the diversity and complexity of Canadian families that was highlighted by the contributions to last year's Special Issue of Canadian Studies in Population (vol. 47, issue 1-2).

Reading Ana Fostik's commentary reminds me of last March, when I was taking calls with the Vanier Institute of the Family to coordinate the 2020 Special Issue of CSIP while I was in lockdown and my young children were attending Zoom school in the background. Those early times were only a preview of the disruptions that the pandemic would bring, especially for working women who have been forced to rethink their professional and personal lives due to the double-burden of job loss and increased care responsibilities. A recent report indicates that, in Canada, by April 2020, twelve times more women than men had left paid work to care for children (Nolan, 2021). Although women's employment rate rebounded during the summer, the Canadian Centre for Policy Alternatives estimates that, by December 2020, women's employment rate $(55.3 \%)$ was still 2.7 percentage points below the rate posted in February 2020, the same level of employment as in 2000 (Scott, 2021).

Among working women, academics like me have been particularly affected by the pandemic (Deryugina et al., 2021; Gabster et al., 2020; Yildirim \& Eslen-Ziya, 2021). It is thus with great sorrow that this double-issue marks the end of my role as Editor-in-Chief a few months earlier than anticipated. Despite my early departure, I am proud to leave Canadian Studies in Population on a path of growth, as the recently released Impact Factor for 2020 demonstrates. This achievement would, of course, not have been possible without our authors, reviewers and readers, to whom I extend my gratitude.

I leave the journal in the trusted hands of Dr. Lisa Schostrein, current president of the Canadian Population Society, and the amazing team at Springer Publishing. I have no doubt that this transition will ensure the journal's continued success in delivering high-quality academic research to scholars nationwide and internationally. 


\section{References}

Berry, I., Soucy, J.-P.R., Tuite, A., \& Fisman, D. (2020). Open access epidemiological data and an interactive dashboard to monitor the COVID-19 outbreak in Canada. CMAJ, 192(15), E420.

Bignami, S. (2021). Le profil démographique de la première vague de la pandémie de la COVID-19 au Québec, in: Victor Piché and Nadine Ouellette, Les enjeux sociaux à la lumière de la démographie, Montréal : Les Presses de l'Université de Montréal. Forthcoming.

Bignami, S., Boujija, Y., Sandberg, J., \& Fisman, D. (2021a). In-person schooling and COVID-19 transmission in Canada's three largest cities. medRxiv. https://www.medrxiv.org/content/10. 1101/2021.03.21.21254064v1; published online March 21, 2021.

Bignami, S., Boujija, Y., Ghio, D., \& Stilianakis, N. (2021b). Beware of regional heterogeneity when assessing the role of schools in the SARS-CoV-2 second wave in Italy. The Lancet Regional Health-Europe, 7, 100174.

Canadian Institute for Health Information (2020). Pandemic experience in the long-term care sector. Retrieved on July 29, 2020 from: https://www.cihi.ca/sites/default/files/document/covid-19rapid-response-long-term-care-snapshot-en.pdf.

Choi, K., Denice, P., Haan, M., \& Zajacova, A. (2021). Studying the social determinants of COVID19 in a data vacuum. Canadian Review of Sociology, 58(2), 146-164.

Décarie, Y., \& Michaud, P. C. (2021). Counting the dead: COVID-19 and mortality in quebec and British Columbia during the first wave. Canadian Studies in Population. https://doi.org/10.1007/ s42650-021-00053-z

Deryugina, T., Schurchkov, O., \& Stearns, J. (2021). COVID-19 disruptions disproportionately affect female academics. AEA Papers and Proceedings, 111, 164-168.

Detsky, A. S., \& Bogoch, I. I. (2020). COVID-19 in Canada: Experience and response. JAMA, 324(8), 743-744.

Etowa, J., Hyman, I., Mbagwu, I., et al. (2021). Strengthening the collection and use of disaggregated data to understand and monitor the risk and burden of COVID-19 among racialized populations. Canadian Studies in Population. https://doi.org/10.1007/s42650-021-00054-y

Fisman, D., Bogoch, I., \& Lapointe-Shaw, L. (2020). Risk factors associated with mortality among residents with coronavirus disease 2019 (COVID-19) in long term care facilities in Ontario. Canada. JAMA Network Open, 3(7), e2015957.

Fostik, A. (2021). COVID-19 and fertility in Canada: A commentary. Canadian Studies in Population. https://doi.org/10.1007/s42650-021-00054-y

Gabster, B. P., van Daalen, K., Dhatt, R., \& Barry, M. (2020). Challenges for the female academic during the COVID-19 pandemic. The Lancet, 395, 1968-1969.

Ghio, D., Acosta, E., Fisman, D. et al. (2021). Population health and COVID-19 in Canada: A demographic comparative perspective. Canadian Studies in Population. https://doi.org/10.1007/ s42650-021-00057-9

Gurdasani, D., Alvani, N. A., Greenhalgh, T., Hyde, Z., et al. (2021). School reopening without robust COVID-19 mitigation risks accelerating the pandemic. The Lancet, 397(10280), 1177-1178.

Karmakar, M., Lantz, P. M., \& Tipirneni, R. (2021). Association of social and demographic factors with COVID-19 incidence and death rates in the US. JAMA Network Open, 4(1), e2036462.

Little, N. (2021). COVID-19 Tracker Canada. Retrieved on July 29, 2021 from: https://covid19tra cker.ca.

Nolan, S. (2021). Women's work undone. Toronto Star, July 27. https://www.thestar.com/news/atkin sonseries/2021/covid-19-womens-work.html.

Peloquin, T. (2020). Des chercheurs dénoncent un «manque criant des données sur la pandémie». $L a$ Presse, April 30. https://www.lapresse.ca/covid-19/2020-04-30/des-chercheurs-denoncent-unmanque-criant-de-donnees-sur-la-pandemie.

Pijls, B. G., Jolani, S., Atherley, A., et al. (2021). Demographic risk factors for COVID-19 infection, severity, ICU admission and death: a meta-analysis of 59 studies. BMJ Open, 11, e044640.

Riffe, Acosta, \& the COVerAGE-DB Team. (2021). Data Resource Profile: COVerAGE-DB: A global demographic database of COVID-19 cases and deaths (COVerAGE-DB). International Journal of Epidemiology, 390-390f

Roser, M., et al. (2021). Coronavirus pandemic (COVID-19). Our world in data. Retrieved on July 27 , 2021 from: https://ourworldindata.org/coronavirus. 
Scott, K. (2021). Women, work and COVID-19. Ottawa: Canadian Centre for Policy Alternatives. Retrieved on July 29, 2021 from: https://www.policyalternatives.ca/publications/reports/womenwork-and-covid19.

Statistics Canada (2021a). Preliminary dataset on confirmed cases of COVID-19, Public Health Agency of Canada, 2020-2021. Retrieved on July 29, 2021, from: https://doi.org/10.25318/ 132600032020001-eng.

Statistics Canada. (2021b). Population estimates on July 1st, 2020, by age and sex. Table: 17-100005-01. Retrieved on July 29, 2021, from: https://www150.statcan.gc.ca/t1/tbl1/en/tv.action? pid $=1710000501$.

Subedi, R., Greenberg, L., \& Turcotte, M. (2020). COVID-19 mortality rates in Canada's ethno- cultural neighbourhoods. Retrieved on July 29, 2021 from: https://www150.statcan.gc.ca/n1/pub/ 45-28-0001/2020001/article/00079-eng.htm.

Yildirim, T. M., \& Eslen-Ziya, H. (2021). The differential impact of COVID-19 on the work conditions of women and men academics during the lockdown. Gender, Work \& Organization, 28(S1), 243-249.

Webster, P. (2020). Canada and COVID-19: Learning from SARS. The Lancet, 395, 936-937.

Publisher's note Springer Nature remains neutral with regard to jurisdictional claims in published maps and institutional affiliations. 